\title{
Three (more) tips to reduce socioeconomic bias in virtual anesthesiology interviews
}

\author{
Laura E. Flores, BA · Roshell Muir, PhD $\cdot$ Kathleen E. Padilla, MS • \\ Manisha Salinas, DrPH · Emily M. Silver, MA · Gianni R. Lorello, BSc, \\ MD, MSc (Med Ed), CIP, FRCPC (1)
}

Received: 21 April 2021/Revised: 21 April 2021 / Accepted: 22 April 2021/Published online: 26 May 2021

(C) Canadian Anesthesiologists' Society 2021

\section{To the Editor,}

We were very interested to read "Six tips for successful virtual anesthesiology interviews in the COVID-19 era and beyond." ${ }^{1}$ Leng et al. provided tips for a smooth virtual interview season, from both the perspective of the program and the interviewee. The authors provided an attractive and comprehensive figure for anesthesiology stakeholders to utilize as they move forward with virtual residency and fellowship interviews. In addition, Leng et al. addressed potential sources of bias by suggesting all interviewers undergo unconscious bias training before interview season. We applaud the authors' commitment to decreasing inequities in residency and fellowship interviews, especially given the disproportionately low proportion of

This letter is accompanied by a reply. Can J Anesth 2021; this issue.

\section{E. Flores, BA}

College of Allied Health Professions, University of Nebraska

Medical Center, Omaha, NE, USA

R. Muir, $\mathrm{PhD}$

Department of Medicine, Division of Infectious Diseases and HIV Medicine, Drexel University College of Medicine,

Philadelphia, PA, USA

K. E. Padilla, MS

School of Criminology and Criminal Justice, Arizona State

University, Phoenix, AZ, USA

M. Salinas, DrPH

Department of Hematology and Oncology, Mayo Clinic,

Jacksonville, FL, USA

E. M. Silver, MA

Department of Psychology, University of Chicago, Chicago, IL, USA the medical workforce from socioeconomically disadvantaged backgrounds. ${ }^{2}$

Suggesting bias training for interviewers is an excellent start, requiring to reflexively engage in dialogue on how subjectivities, social locations, prior world views, and knowledge may bias interviewers. We offer three additional "key tips" for successful virtual anesthesiology interviews. We believe adding these tips will help address potential sources of inequity and bias, while helping to increase socioeconomic diversity within the field.

Internet access is a crucial, yet under-appreciated topic related to the increasing demand for virtual interviews. With over $40 \%$ of the global population unable to access

G. R. Lorello, BSc, MD, MSc (Med Ed), CIP, FRCPC ( $\square)$. Department of Anesthesiology and Pain Medicine, University of Toronto, Toronto, ON, Canada

e-mail: Gianni.Lorello@uhn.ca

Department of Anesthesia and Pain Management, University Health Network - Toronto Western Hospital, Toronto, ON, Canada

The Wilson Centre, University Health Network, Toronto, ON, Canada

Women's College Research Institute, Women's College

Hospital, Toronto, ON, Canada 


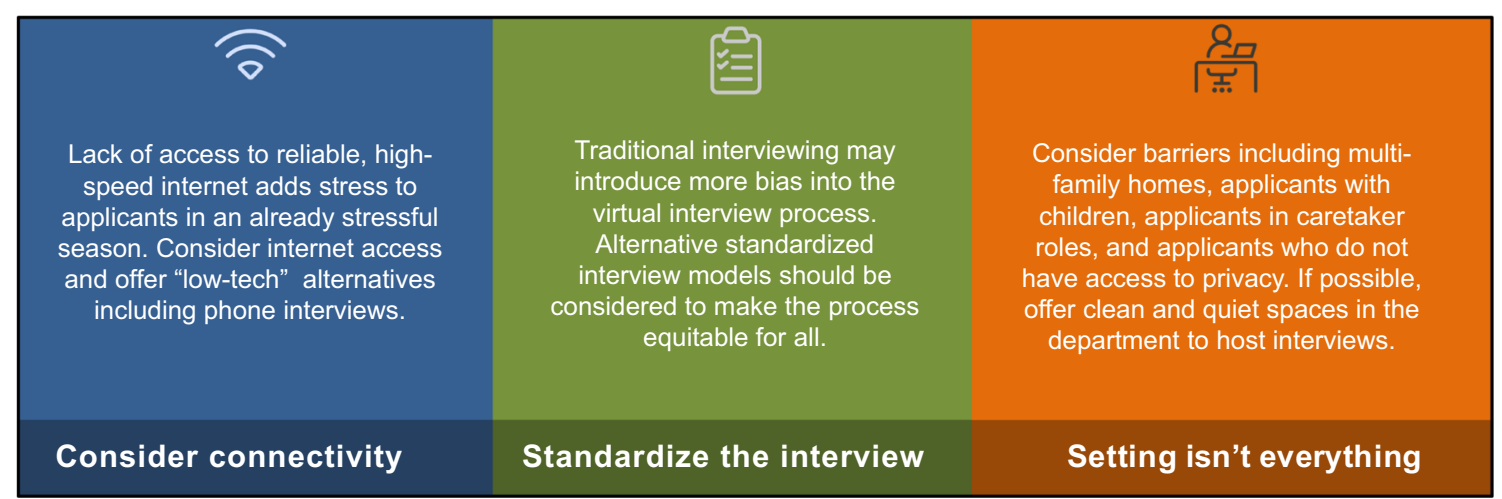

Figure Three tips to reducing socioeconomic bias in virtual interviews

reliable internet, ${ }^{\mathrm{A}}$ stakeholders must consider that trainees may not have the reliable, high-speed internet required for seamless virtual interviews in their homes. ${ }^{3}$ Candidates without access are severely disadvantaged compared with their peers because of the potential for low video quality, increased glitches, or inability to access video conferencing platforms altogether, each introducing barriers to success. ${ }^{4}$ As we aim for equity in this process, we would add Tip 7: Consider connectivity.

As Nwora et al. suggest, the interview process itself may introduce potential bias against populations who are already underrepresented in medicine, and using standardized interviews might be a better alternative. ${ }^{5}$ There are many options for standardized interviews that are considered fairer by interviewers and applicants alike, and we believe anesthesiology programs should consider adopting Tip 8: Standardize the interview.

We also recommend anesthesiology programs consider offering office space for applicants attending virtual interviews. Pourmand et al. suggest bright lighting and adequate computer angles make for a more successful interview experience. ${ }^{4}$ Nevertheless, interviewees may live in spaces they are uncomfortable exposing on camera or may have other conflicts such as multi-family homes, children, other caretaking responsibilities, or lack of privacy. These settings pose significant barriers to an inclusive interview process and should be mitigated by the program rather than the onus being placed on the applicant. We therefore propose all parties consider Tip 9: Setting isn't everything.

By adding these tips to the already strong framework developed by Leng et al., we are optimistic anesthesiology programs will be better equipped to handle virtual

\footnotetext{
${ }^{\text {A }}$ United Nations Educational, Scientific and Cultural Organization. New report on global broadband access underscores urgent need to reach the half of the world still unconnected. UNESCO, 2 June 2020. Available from URL: https://en.unesco.org/news/new-report-globalbroadband-access-underscores-urgent-need-reach-half-world-stillunconnected (accessed April 2021).
}

interviews while considering socioeconomic diversity of their applicant pool.

Acknowledgements The authors thank Dr. Julie Silver for her continued mentorship, support, and dedication to the advancement of equity in the medical workforce. Dr. Gianni R. Lorello thanks Dr. Julie Silver for the opportunity to mentor and sponsor the listed authors; he also thanks the Department of Anesthesia and Pain Management at the University Health Network - Sinai Health System for the continued support and academic time.

Disclosures None.

\section{Funding statement None.}

Editorial responsibility This submission was handled by Dr. Stephan K.W. Schwarz, Editor-in-Chief, Canadian Journal of Anesthesia/Journal canadien d'anesthésie.

\section{References}

1. Leng JC, Mariano ER, El-Boghdadly K. Six tips for successful virtual anesthesiology interviews in the COVID-19 era and beyond. Can J Anesth 2021; DOI: https://doi.org/10.1007/ s12630-021-01977-5

2. Youngclaus J, Roskovensky L. An updated look at the economic diversity of U.S. medical students. AAMC. 2018. Available from URL: https://www.aamc.org/data-reports/analysis-brief/report/ updated-look-economic-diversity-us-medical-students (accessed April 2021).

3. Seah KM. COVID-19: Exposing digital poverty in a pandemic. Int J Surg 2020; 79: 127-8.

4. Pourmand A, Lee H, Fair M, Maloney K, Caggiula A. Feasibility and usability of tele-interview for medical residency interview. West J Emerg Med 2018; 19: 80-6.

5. Nwora C, Allred DB, Verduzco-Gutierrez M. Mitigating bias in virtual interviews for applicants who are underrepresented in medicine. J Natl Med Assoc 2021; 113: 74-6.

Publisher's Note Springer Nature remains neutral with regard to jurisdictional claims in published maps and institutional affiliations. 